\title{
Nitriding of tetragonal zirconia in a high current d.c. plasma source.
}

\author{
T. Delachaux ${ }^{1 *}$, Ch. Hollenstein ${ }^{1}$, F. Lévy ${ }^{2}$, C. Verdon ${ }^{3}$ \\ ${ }^{1}$ EPFL-Centre de Recherches en Physique des Plasmas, CH-1015 Lausanne, Switzerland \\ ${ }^{2}$ EPFL-Institut de Physique Appliquée, CH-1015 Lausanne, Switzerland \\ ${ }^{3}$ Asulab S.A., Rue des Sors 3, 2074 Marin, Switzerland \\ *e-mail: thierry.delachaux@epfl.ch
}

\begin{abstract}
:
Surface nitriding of tetragonal zirconia $\left(\mathrm{t}-\mathrm{ZrO}_{2}\right)$ has been performed with the aim of combining the optical properties of zirconium nitride $(\mathrm{ZrN})$ with the hardness and toughening properties of tetragonal zirconia. A high current d.c. arc plasma source has been used to create a reactive environment of atomic hydrogen and $\mathrm{NH}$ radicals. Plasma analysis showed that a highly reductive atmosphere is necessary to transform the tetragonal zirconia. X-ray diffraction and transmission electron microscopy analysis show an efficient transformation of the $\mathrm{t}-\mathrm{ZrO}_{2}$ at the surface which exhibits the typical yellow-gold color of $\mathrm{ZrN}$ and high wear resistance. For a 2 hours treatment at $750{ }^{\circ} \mathrm{C}$ the nitriding is accompanied by the formation of a $250 \mathrm{~nm}$ thick gradient layer of $\mathrm{ZrN}$ structure and a partial transformation of $\mathrm{t}-\mathrm{ZrO}_{2}$ into cubic zirconia deeper in the bulk.
\end{abstract}

Keywords: Zirconia, Nitrides, Plasma processing and deposition, Glow discharge 


\section{Introduction}

Zirconium nitride $(\mathrm{ZrN})$ is a refractory material which is hard (Vickers hardness: $15 \mathrm{GPa}$ ), shows good chemical resistance, has good electrical conductivity and is of gold-like color [1, 2]. These properties make the use of zirconium nitride interesting for various applications such as protective coatings on cutting tools, diffusion barrier in integrated circuits, electrical contacts or as decorative coating. In this latter case, it is desirable to obtain layers possessing both coloring and mechanical functionality, such as good wear resistance and resistance to cracks and shocks. To achieve this goal, the best solution would be to surface nitride a hard material having a high toughness. This kind of process avoids the adhesion problems of coatings as well as it will take advantage of the bulk material mechanical properties. For producing $\mathrm{ZrN}$ layers, zirconia is an interesting starting material due to the possibility of retaining its high temperature phases (cubic and tetragonal) at room temperature by adequate doping. In particular, the tetragonal phase of zirconia $\left(\mathrm{t}-\mathrm{ZrO}_{2}\right)$ doped with $3 \mathrm{~mol} \% \mathrm{Y}_{2} \mathrm{O}_{3}$ develops high hardness and toughness (Vickers hardness: $13 \mathrm{GPa}$, fracture toughness: 6-12 $\mathrm{MPa} \mathrm{m}^{1 / 2}$ [3]) which is well suited to the decorative layer applications. Processes using thermal treatments in a nitrogen atmosphere [4] or solid-state reaction [5, 6] with zirconia have been reported. However, in these cases essentially zirconium-oxynitride phases are formed with only few $\mathrm{ZrN}$ precipitates which are not sufficiently dense to form a zirconium nitride layer exhibiting the gold color. The techniques used so far to produce zirconium nitride layers are based on thin film deposition $[7,8]$ or on the direct surface nitriding of zirconium substrates by plasmas $[9,10]$. However, zirconium is soft (Vickers hardness: $\sim 0.1$ $\mathrm{GPa}$ ) and would be deformed much easier than $\mathrm{t}-\mathrm{ZrO}_{2}$ when strained.

In this paper, we report on the achievement of surface nitriding of zirconia by using an efficient plasma source for reactive species production, which allows chemical processing of the samples without any bias voltage, thus avoiding damage to the surface by ion bombardment.

\section{Experimental}

Commercial polycrystalline yttria-stabilized ( $3 \mathrm{~mol} \%$ ) zirconia powder, produced by Tosoh, were used and shaped by injection moulding using a commercial polyacetal based binder to form samples $2 \mathrm{~mm}$ thick, $6 \mathrm{~mm}$ large and $19 \mathrm{~mm}$ long. They were sintered at $1500{ }^{\circ} \mathrm{C}$ under air for 1 hour. The so obtained ceramics had a grain size of $0.3 \mu \mathrm{m}$. An industrial plasma reactor of the type Balzers BAI $450 \mathrm{D}$ [11], whose simplified scheme is given in fig. 1, was used to nitride the zirconia. The non-self sustained DC discharge is maintained between a heated tungsten filament and a water-cooled copper anode, $50 \mathrm{~cm}$ apart. Magnetic coils in Helmholtz configuration generating a 100 Gauss field are used to increase the electron density $\left(\sim 10^{18} \mathrm{~m}^{-3}\right.$ on axis). The discharge current can be varied from 50 to $250 \mathrm{~A}$ and the discharge voltage is $50-90 \mathrm{~V}$. The treatments were made in a gas mixture of argon-nitrogen-hydrogen or argon-ammonia. A constant argon flow of $1200 \mathrm{sccm}$ injected in the filament chamber was used to maintain a low discharge voltage. The hydrogen, nitrogen and ammonia gas flow could be varied between 0 and $1000 \mathrm{sccm}$. The working pressure was measured by a baratron gauge and was kept constant at 1.5 mbar by regulating the pumping speed. The zirconia samples were placed in a cylindrical arrangement at a distance of $11 \mathrm{~cm}$ from the axis of the discharge, out of the discharge plasma but in the diffusion region of the reactive species. The substrate temperature is given by the equilibrium between the heating due to recombination of atomic species on the surface and cooling by radiative and conduction losses [11]. Typical processing conditions were at an arc current of $110 \mathrm{~A}$, flowrates of $1200 \mathrm{sccm}$ for Ar, 250 
sccm for $\mathrm{N}_{2}$ and $750 \mathrm{sccm}$ for $\mathrm{H}_{2}$ in $\mathrm{Ar}-\mathrm{N}_{2}-\mathrm{H}_{2}$ mixtures. With ammonia, an arc current of 110 A was used with flowrates of $1200 \mathrm{sccm}$ for $\mathrm{Ar}$ and $410 \mathrm{sccm}$ for $\mathrm{NH}_{3}$.

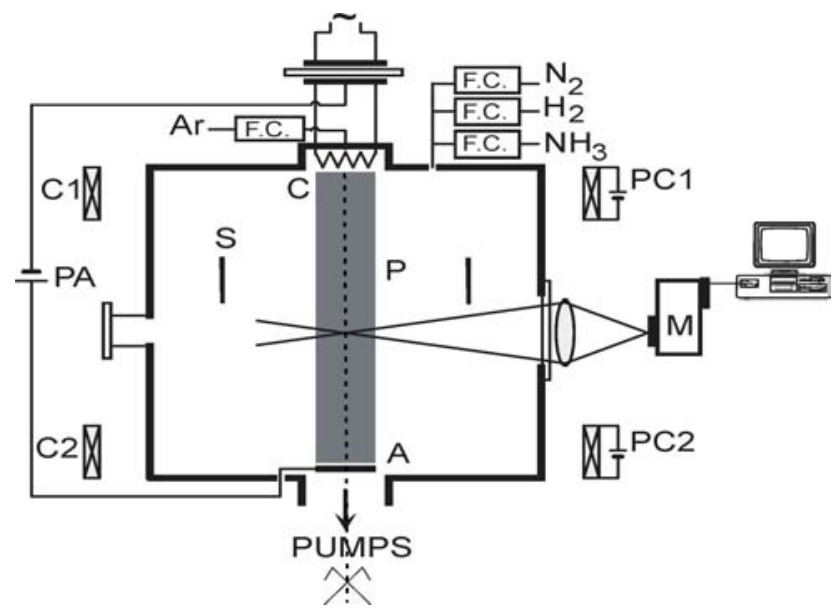

Figure 1: Cross section of the experimental arrangement. A: anode, C: cathode, P: plasma, PA: arc power supply, $\mathrm{C} 1$ and $\mathrm{C} 2$ : coils, PC1 and PC2: coil power supplies, F.C.: flow controllers, S: substrates, M: monochromator.

Structural modifications induced by the process have been characterized by X-ray diffraction (XRD) (Rigaku apparatus using the copper $\mathrm{K} \alpha 1$ and $\mathrm{K} \alpha 2$ lines) and a Philips CM20 transmission electron microscopy (TEM) used in bright field. TEM cross section samples were prepared by mechanical grinding and ion milling. Plasma analysis was performed by optical emission spectroscopy using a $0.275 \mathrm{~m}$ monochromator with a grating of 1200 grids $/ \mathrm{mm}$ of $0.2 \mathrm{~nm}$ wavelength resolution and a Peltier-cooled CCD detector.

\section{Results and discussion}

Fig. 2 shows grazing angle $\left(1^{\circ}\right)$ XRD spectra from the surface of a non-treated and a treated ceramic which was typically nitrided during 2 hours at a sample temperature of $750{ }^{\circ} \mathrm{C}$. The measurements show modifications of the crystallographic structure between the original tetragonal zirconia and the treated one. Firstly, the new diffraction lines that appear on the nitrided samples on fig. $2 b(\mathrm{c}-\mathrm{ZrN})$ show the characteristic NaCl-type structure indicating the formation of $\mathrm{ZrN}$. Secondly, small changes in the $\mathrm{t}-\mathrm{ZrO}_{2}$ structure are evidenced. In the doublet lines such as t-(002) and t-(200), t-(202) and t-(220) or t-(113) and t-(311), the lowest diffraction angle lines decrease. The diminishing of these lines indicates that the nitriding process also transforms the tetragonal structure of zirconia into cubic $\left(\mathrm{c}-\mathrm{ZrO}_{2}\right)$. This effect is already known for the zirconium oxynitride in the Y-Zr-N-O system $[4,5,6]$, where nitrogen acts as a stabilizer which adds to yttria to retain the cubic form of $\mathrm{ZrO}_{2}$. This structure is formed when there is not sufficient nitrogen inside the zirconia to transform into the zirconium nitride structure [12]. The crystallographic modifications involved by the nitriding process on $\mathrm{t}-\mathrm{ZrO}_{2}$ are therefore changing from $\mathrm{t}-\mathrm{ZrO}_{2} \rightarrow \mathrm{c}-\mathrm{ZrO}_{2} \rightarrow \mathrm{ZrN}$ with increasing nitrogen concentration. 


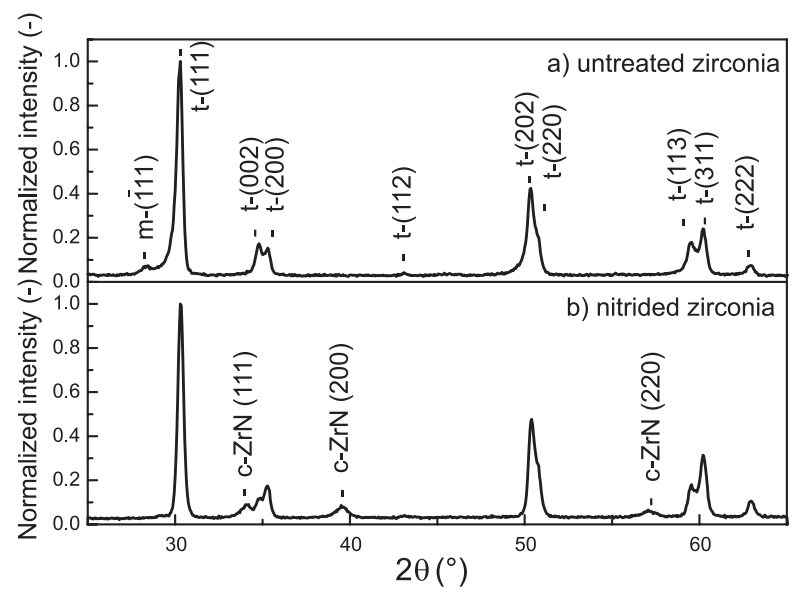

Figure 2: X-ray diffraction spectra of a) non-treated $\mathrm{t}-\mathrm{ZrO}_{2}, \mathrm{~b}$ ) nitrided zirconia at typical plasma conditions $\left(\mathrm{I}_{\mathrm{arc}}: 110 \mathrm{~A}, \phi_{\mathrm{Ar}}: 1200 \mathrm{sccm}, \phi_{\mathrm{H} 2}: 750 \mathrm{sccm}, \phi_{\mathrm{N} 2}: 250 \mathrm{sccm}\right)$. Identification of the diffraction lines are marked: $t$ and $\mathrm{m}$ represent the tetragonal and monoclinic phases, respectively, of $\mathrm{ZrO}_{2}$ and c- $\mathrm{ZrN}$ : the cubic phase of $\mathrm{ZrN}$.

Modifications in the structure of the nitrided zirconia were analysed on a TEM cross section. Fig. 3 shows a transformation close to the surface. The modified surface layer is about 250 $\mathrm{nm}$ thick and shows a clear difference in comparison with the underlying structure where the zirconia grains $(\sim 300 \mathrm{~nm}$ wide) are visible. Small grains which nucleated in that layer are responsible for the contrast. They were identified by selected area diffraction as of $\mathrm{ZrN}$ structure, embedded in a mixture of $\mathrm{c}-\mathrm{ZrO}_{2}$ and $\mathrm{t}-\mathrm{ZrO}_{2}$. It was also observed that $\mathrm{c}-\mathrm{ZrO}_{2}$ can be found deeper than this layer due to a sufficient nitrogen concentration to form this phase. However, the exact nitrogen profile has still to be investigated. This is of importance since it influences the mechanical properties of the final treated samples by the modified structure it implies.

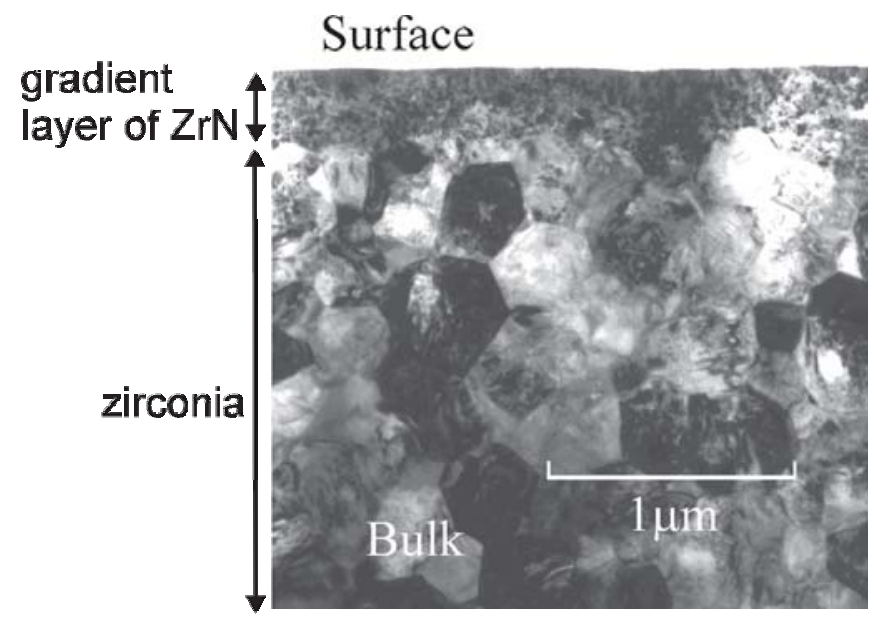

Figure 3: Transmission electron microscopy (TEM) cross section of nitrided zirconia at typical plasma conditions ( $\mathrm{I}_{\text {arc }}: 110 \mathrm{~A}, \phi_{\mathrm{Ar}}: 1200 \mathrm{sccm}, \phi_{\mathrm{H} 2}: 750 \mathrm{sccm}, \phi_{\mathrm{N} 2}: 250$ $\mathrm{sccm}$ ). It shows the nitrided structure $\sim 250 \mathrm{~nm}$ from the surface and the zirconia grains deeper.

Optically, the samples shown in fig. 3 exhibited a yellow gold color. Colorimetry measurements performed with the CIELAB D65 color reference system for an observer at an 
angle of 2 degrees give for the colorimetric coordinates: $\left(a^{*}, b^{*}, L^{*}\right)=(1.3,29.9,73.3)$. For comparison, a thin coating of gold under the same conditions of measurements give: $\left(a^{*}, b^{*}\right.$, $\left.L^{*}\right)=(3.3,32.9,90.3)$. The measured differences are significant for the brightness variable $L^{*}$. To the eyes, it means that our nitrided zirconia samples are only slightly darker than gold. The mechanical wear of the samples was tested during 48 hours in an abrasive bath made of alumina chips (industrial test simulating the wearing of jewelry coatings for several years). After this severe abrasive test the samples had no noticeable changes in coloring and no delamination, therefore exhibiting a high wear resistance as expected for surface nitriding of the tetragonal zirconia.

The process developed is very efficient to nitride zirconia in comparison with thermal processes, for instance. In order to identify the species present in the plasma phase and to clarify the nitriding mechanism, optical emission spectroscopy was performed. We observed that it is possible to nitride zirconia in an argon-ammonia plasma as well as in a mixture of argon-nitrogen-hydrogen, but not in an argon-nitrogen plasma. Fig. 4a shows a typical optical emission spectrum for a nitriding plasma (in that case a Ar- $\mathrm{N}_{2}-\mathrm{H}_{2}$ mixture), while fig. $4 \mathrm{~b}$ shows a spectrum for a Ar- $\mathrm{N}_{2}$ plasma. In both spectra the first $\left(\mathrm{N}_{2} 1^{\text {st }}+\right)$ and second positive systems $\left(\mathrm{N}_{2} 2^{\text {nd }}+\right)$ of the excited nitrogen are present. However the main difference is in the production of atomic hydrogen and $\mathrm{NH}$ species in the nitrogen-hydrogen plasma. The absence of any molecular hydrogen bands indicates a high degree of hydrogen dissociation. Atomic hydrogen is therefore required to react directly with the zirconia in particular with the oxygen, and it is also used for abundant NH production in the gas phase. The oxygen reduction by atomic hydrogen can be evidenced when the zirconia is exposed to a hydrogen plasma: after a few minutes the zirconia shows a grey-black coloring which is a sign of understoichiometry in oxygen. Plasma treatment with hydrogen-nitrogen mixtures up to a ratio of $5 \% / 95 \% \mathrm{~N}_{2} / \mathrm{H}_{2}$ still shows the yellow gold coloring and exhibits the $\mathrm{ZrN}$ crystalline structure at the surface. In contrast, treatment in nitrogen plasmas gave samples without noticeable surface modifications: the color remained close to the original white of the zirconia and no $\mathrm{ZrN}$ crystalline structure was found by XRD. The importance of a reductive atmosphere was also noticed by Cheng and Thompson. [6] where a graphite resistance furnace was used and carbon was added to zirconia samples to accelerate the process of oxygen-nitrogen exchange to form oxynitride phases of zirconium. From a thermodynamic point of view, this can be understood by the fact that $\mathrm{ZrO}_{2}$ is more stable than $\mathrm{ZrN}$ (Gibbs free energy for standard conditions: $\Delta \mathrm{G}_{\mathrm{f}}^{0}(\mathrm{ZrN}) \sim-315 \mathrm{~kJ} / \mathrm{mol}$ and $\Delta \mathrm{G}_{\mathrm{f}}^{0}\left(\mathrm{ZrO}_{2}\right) \sim-1020 \mathrm{~kJ} / \mathrm{mol}$ [13]); so to create $\mathrm{ZrN}$, one has first to remove the oxygen before nitrogen incorporation.

Our studies show that in the type of reactor used, the Ar- $\mathrm{NH}_{3}$ and the $\mathrm{Ar}-\mathrm{N}_{2}-\mathrm{H}_{2}$ plasma processes have a comparable efficiency provided that the flowrate ratio of $\mathrm{N}_{2} / \mathrm{H}_{2}$ lies between $5 \% / 95 \%$ and $95 \% / 5 \%$. The optical emission spectroscopy measurements of these plasmas have the same features as the spectra of fig. 4a, varying only in magnitude with the $\mathrm{N}_{2} / \mathrm{H}_{2}$ ratio; in the same time, no major differences are noticed in the wear and coloring of the nitrided zirconia under those different conditions. In both kinds of plasma, then, it seems that the production of the reactive species $\left(\mathrm{N}, \mathrm{H}, \mathrm{NH}\right.$ and $\left.\mathrm{NH}_{2}\right)$ is sufficient for surface reaction. 




Figure 4: a) Typical optical emission spectrum obtained in a nitriding plasma discharge of Ar$\mathrm{N}_{2}-\mathrm{H}_{2}$ mixture at typical plasma conditions $\left(\mathrm{I}_{\mathrm{arc}}: 110 \mathrm{~A}, \phi_{\mathrm{Ar}}: 1200 \mathrm{sccm}, \phi_{\mathrm{H} 2}: 750\right.$ $\left.\mathrm{sccm}, \phi_{\mathrm{N} 2}: 250 \mathrm{sccm}\right)$. b) Optical emission spectrum of a non nitriding plasma of Ar- $\mathrm{N}_{2}$ at $\left.\mathrm{I}_{\text {arc }}: 110 \mathrm{~A}, \phi_{\mathrm{Ar}}: 1200 \mathrm{sccm}, \phi_{\mathrm{N} 2}: 3750 \mathrm{sccm}\right)$.

\section{Conclusions}

In conclusion, we have demonstrated efficient surface nitriding of tetragonal zirconia by use of a high current d.c. arc plasma. The nitriding is accompanied by the formation of a $250 \mathrm{~nm}$ thick gradient layer of $\mathrm{ZrN}$ structure and a partial transformation of $\mathrm{t}-\mathrm{ZrO}_{2}$ into c- $\mathrm{ZrO}_{2}$ deeper in the bulk. Atomic hydrogen is found to be necessary to efficiently remove the oxygen, whereas $\mathrm{N}, \mathrm{NH}$ or $\mathrm{NH}_{2}$ is probably the nitriding specie. The treated ceramics combine the mechanical bulk properties of $\mathrm{t}-\mathrm{ZrO}_{2}$ with the optical properties of $\mathrm{ZrN}$, with no cracks and a good wear resistance and resistance to shocks. These are therefore well suited for decorative purposes.

\section{Acknowledgments}

The authors gratefully acknowledge the financial support of the CTI Swiss Federal Research grant CTI No.3579.1.

\section{References:}

[1] L.E. Toth, Transition Metal Carbides and Nitrides, Academic Press, 1971.

[2] H.O. Pierson, Handbook of Refractory Carbides and Nitrides, Noyes Publications, 1996.

[3] Y.-M. Chiang, D.P. Birnie III, W.D. Kingery, Physical Ceramics, John Wiley \& Sons, Inc., 1997.

[4] J. Wrba, M. Lerch, J. Eur. Ceram. Soc. 18 (1998) 1787.

[5] J.-C. Gilles, Bull. Soc. Chim. Fr. 22 (1962) 2118.

[6] Y. Cheng, D.P. Thompson, Special Ceramics 9 (1992) 149. 
[7] P.C. Johnson, H.Randhawa, Surf. Coat. Technol. 33 (1987) 53.

[8] W.H. Soe, T. Kitagaki, H. Ueda, N. Shima, M. Otsuka, R. Yamamoto, Mat. Res. Soc. Symp. Proc. 458 (1997) 379.

[9] T. Hino, I. Fujita, M. Nishikawa, Plasma Sources Sci. Technol. 5 (1996) 424.

[10] L. Pichon, A. Straboni, T. Girardeau, M. Drouet, P. Widmayer, J. Appl. Phys. 87(2000) 925.

[11] J. Karner, M. Pedrazzini, Ch. Hollenstein, Diamond Relat. Mater. 5 (1996) 217.

[12] Y. Cheng, D.P. Thompson, J. Am. Ceram. Soc. 76 (1993) 3683.

[13] R.C. Weast (Editor), Handbook of Chemistry and Physics (1977-1978), CRC Press, Inc., Ohio, USA, 1977. 